\title{
ПРОФЕССИОНАЛЬНЫЕ РИСКИ ХИРУРГИЧЕСКОГО И ОРТОПЕДИЧЕСКОГО ЛЕЧЕНИЯ ПАЦИЕНТОВ С ПРИОБРЕТЕННЫМИ ДЕФЕКТАМИ ЛИЦА И ЧЕЛЮСТЕЙ (ОБЗОР ЛИТЕРАТУРЫ)
}

\author{
OCCUPATIONAL RISKS IN THE REHABILITATION OF PATIENTS WITH \\ ACQUIRED DEFECTS OF THE FACE AND JAW (REVIEW OF LITERATURE)
}

\author{
С.Д. Арутюнов ${ }^{1}$, В.К. Леонтьев ${ }^{1}$, А.В. Цимбалистов ${ }^{2}$, А.Ю. Дробышев ${ }^{1}$, \\ Л.М. Барденштейн ${ }^{1}$, А.Э. Харазян ${ }^{1}$, А.С. Рапута ${ }^{2}$, В.Н. Царев ${ }^{1}$ \\ S.D. Arutyunov ${ }^{1}$, V.K. Leontiev ${ }^{1}$, A.V. Tsimbalistov ${ }^{2}$, A.Yu. Drobyshev ${ }^{1}$, \\ L.M. Bardenshtein ${ }^{1}$, A.E. Kharazyan ${ }^{1}$, A.C. Raputa ${ }^{2}$, V.N. Tsarev ${ }^{1}$ \\ ${ }^{1}$ Московский государственный медико-стоматологический университет \\ имени Е.А. Евдокимова, \\ Россия, 127473, г. Москва, ул. Делегатская, д. 20, стр. 1 \\ 2 Белгородский государственный национальный исследовательский университет, \\ Россия, 308015, г. Белгород, ул. Победы, 85
}

\author{
${ }^{1}$ Moscow State Medical and Dental University named after E.A. Evdokimova, \\ 20/1 Delegatskaya St., Moscow, 127473, Russia \\ ${ }^{2}$ Belgorod National Research University, \\ 85 Pobedy St., Belgorod, 308015, Russia
}

E-mail: sd.arutyunov@mail.ru

\begin{abstract}
Аннотация
Представлен обзор современных литературных сведений о проблеме профессиональных рисков, возникающих в деятельности врачей-стоматологов в процессе реабилитации онкостоматологических больных. Выделены основные элементы реабилитационного процесса, при реализации которых могут возникать ситуации, которые рассматриваются с позиций профессиональных рисков. Определены факторы, влияющие на эффективность реабилитационного процесса и повышающие вероятность профессиональных рисков. Особое внимание уделено проблеме создания качественных протезов челюстей и лица, их эстетических характеристикам. Подробно рассмотрены вопросы выбора метода окрашивания силикона - основного материала эпитеза, идентичности воспроизведения парных органов лица (ушной раковины, глазного яблока, орбиты), репродукции мультиорганных сегментов лица. Важным фактором, влияющим на ретенцию протеза, является размер дефекта челюсти и лица, протяженность его границ в функционально активных зонах. Рассмотрены основные механизмы фиксации эктопротезов, в том числе с использованием адгезивных систем на основе силиконов или водорастворимых эмульсий, а также с применением магнитных или балочно-замковых элементов с опорой на онко- и краниальные имплантаты.
\end{abstract}

\begin{abstract}
A review of current literary information on the problem of occupational risks arising in the activities of dentists during the rehabilitation of cancer patients is presented. The main elements of the rehabilitation process are identified, during the implementation of which situations may arise that are considered from the perspective of professional risks. The factors affecting the effectiveness of the rehabilitation process and increasing the likelihood of occupational risks are identified. Particular attention is paid to the problem of creating high-quality dentures of the jaw and face, their aesthetic characteristics. The questions of the choice of the method of dyeing silicone which was the basic material of the epithesis, the identity of the reproduction of paired organs of the face (auricle, eyeball, orbit), reproduction of multiorgan segments of the face, are examined in detail. An important factor affecting the retention of the prosthesis is the size of the defect of the jaw and face, the length of its borders in functionally active
\end{abstract}


zones. The main mechanisms of fixation of ectoprostheses are considered, including using adhesive systems based on silicones or water-soluble emulsions, as well as using magnetic or bar attachment elements which are oncological and cranial implant-supported.

Ключевые слова: профессиональные риски, реабилитация онкостоматологических пациентов, послеоперационные дефекты лица и челюстей, челюстно-лицевая хирургия и ортопедическая стоматология.

Keywords: occupational risks, rehabilitation of onkostomatological patients, postoperative defects of the face and jaw, maxillofacial surgery and prosthetic dentistry.

\section{Введение}

Онкоэпидемиологическими исследованиями последних лет установлен рост злокачественных новообразований головы и шеи среди населения Земли, несмотря на значительные достижения медицины, фармацевтической индустрии и государственную социально-экономическую поддержку во многих развитых странах мира. Усилия современной медицины и политики государств, заботящихся о своих гражданах, направлены на профилактику рака, организацию и управление деятельности медицинских организаций. Ущерб, связанный с онкозаболеваниями, существенен и тяжким бременем ложится на экономику страны, что обусловливает целенаправленный поиск решений, оптимизирующих лечение пациентов с заболеваниями онкологического генеза [Арутюнов и др., 2009; Арутюнов, 2012; Гвоздикова, 2017].

На эффективности качества лечения сказываются риски, которые неизбежны в профессиональной деятельности врача любой специальности. Сегодня сформировалось целое направление управления этими рисками, которое называется риск-менеджментом, позволяющее предвосхитить или установить возможности возникновения случайных событий, дать оценку масштабности и объемности наносимого урона здоровью и угрозе жизни [Есиркепов, 2014; Кондратова, 2016]. Профессиональные риски при ведении тяжелых, в частности, онкологических больных, неотвратимо сопряжены с ошибками, осложнениями течения заболевания, неизбежными конфликтами и разбирательствами. Профессиональные врачебные риски - это ожидаемое событие, последствия которого врач должен стремиться минимизировать своими знаниями и профессионализмом [Леонтьев, 2010; Кондратова, 2016], несмотря на то, что на этапах реабилитации онкостоматологических пациентов они особенно высоки и, как правило, непрогнозируемые.

По данным ВОЗ, ежегодно онкологические заболевания являются причиной смерти более 7,5 млн человек. Ежегодно в России около 190 тыс. человек впервые регистрируются как инвалиды по онкозаболеванию (I - 30 \%, II - 55 \% и III группа - 15 \%). Выявлен бесспорный рост онкозаболеваемости головы и шеи. Причем пациенты этой категории, как правило, трудоспособного возраста, выбывают из социума, становятся инвалидами, которые нуждаются в опеке окружающих и государства. Данный факт побуждает к поиску эффективных методов комплексной реабилитации онкобольных, что сопряжено с серьезными экономическими затратами и социальными усилиями [Арутюнов и др., 2009; Карасева, 2014; Гвоздикова, 2017].

Обеспокоенность и повышенное внимание к онкологии обусловлены устойчивой тенденцией роста онкозаболеваний во всем мире, обусловленной многими факторами, среди которых наиболее важны экологические, экономические и старение населения. Ежегодно в России более 185 тыс. онкобольных впервые признаются инвалидами [Каприн и др., 2013].

В 2016 г. в России прирост впервые в жизни выявленных случаев злокачественных новообразований по сравнению с 2015 г. составил 1,7\%, а с 2006 г. - 20,6 \% [Каприн и др., 2017]. 
Реабилитация пациентов с приобретенными дефектами и деформациями лица и челюстей занимает особое место в современной стоматологии и является одной из приоритетных ее задач, так как наряду с онкозаболеваниями увеличивается число пациентов, нуждающихся в хирургических операциях, связанных с производственным и бытовым травматизмом, дорожно-транспортными происшествиями, техногенными катастрофами, локальными вооруженными конфликтами [Нуриева, Филимонова, 2008; Арутюнов и др., 2009]. Поэтому от челюстно-лицевых хирургов и врачей-стоматологов-ортопедов требуется высокий профессионализм и минимизация профессиональных рисков при ведении этой сложнейшей категории пациентов.

Основным методом лечения злокачественных опухолей лица и челюстей является комбинированный подход, включающий хирургическое вмешательство, лучевую и/или химиотерапию. Несмотря на современный высокий уровень пластической хирургии и хирургической техники, объем вмешательства настолько обширен, что приводит к обезображиванию внешнего вида пациента [Нуриева, Филимонова, 2008; Задеренко и др., 2010; Дробышев и др., 2014; Buzayan, 2013]. У пациентов с приобретенными дефектами лица и челюстей неизбежно развиваются функциональные нарушения из-за расстройства дыхания, глотания и звукообразования, а также эстетические нарушения, приводящие к ограничениям жизнедеятельности, социальной дезадаптации и выраженным пограничным психическим нарушениям с доминированием депрессивных и тревожных расстройств (F30-F39; F40-F41, МКБ-10) [Михайлова и др., 1997; Макаревич, 2009; Арутюнов, 2012; Харазян и др., 2019].

В связи с этим высока потребность в персонифицированной реабилитации этого контингента пациентов, которая нередко сопряжена с профессиональными врачебными рисками из-за множества проблем, связанных с планированием, выбором протокола реабилитации, технологии протезирования, практическим отсутствием психотерапевтического, психофармакотерапевтического и социального сопровождения до, на этапах и после лечения [Асташина, 2009; Арутюнов, 2012].

Морфологические особенности структуры и особенности сложного анатомического строения лица и зубочелюстного аппарата усложняют задачу реконструкции после обезображивающих хирургических операций на голове и шее по поводу новообразований и травмы различного генеза. Первичная и вторичная пластика - это сложные по осуществлению, продолжительные по времени и серьезно травмирующие реконструктивные операции, которые возможно выполнить только в высокоспециализированных клиниках [Геворкян и др., 2007]. Всё это определяет актуальность проблемы лечения и реабилитации больных с приобретенными челюстно-лицевыми дефектами и рост потребности в специализированной стоматологической помощи методами челюстно-лицевого протезирования.

Цель работы - обобщение сведений из научной литературы о возможных профессиональных рисках на этапах реабилитации пациентов с приобретенными дефектами лица и челюстей, о современных достижениях в создании эффективной инновационной организационно-управленческой и медико-технологической модели реабилитации этого контингента больных.

\section{Материалы и методы}

Проведен анализ научной литературы по исследуемой проблеме. Использованы электронные ресурсы Medline (PubMed), eLIBRARY.ru.

\section{Характеристика профессиональных рисков}

Приобретенные дефекты лица и челюстей возникают вследствие травмы и сложных объемных послеоперационных врачебных вмешательств, ведут к уродству, деформации и дисфункции зубочелюстного аппарата, заболеваниям мышц жевательной мускула- 
туры и височно-челюстного сустава [Козицына и др., 2005; Арутюнов и др., 2009; Карасева, 2014].

Анализ литературных данных по комплексной реабилитации онкостоматологических пациентов позволяет выделить особенности и последовательность этапов челюстнолицевого хирургического вмешательства и стоматологическое ортопедическое лечение. Реабилитация этого контингента пациентов - сложнейшая задача, которая сопряжена с этиологией и патогенезом причинного заболевания и основными профессиональными рисками в деятельности врачей всех задействованных специальностей, участвующих в реабилитации этого контингента пациентов. Основные врачебные профессиональные риски, возникающие на этапах лечебно-реабилитационных мероприятий, были структурированы по группам и соотнесены с проблемами организационно-управленческого характера, индивидуальными медико-биологическими особенностями, которые связаны с иммунологическим и микробиологическим статусом, непереносимостью стоматологических материалов пациентами, их психосоматическим анамнезом, комплексностью диагностического ресурса, сложностью и длительностью лечебно-реабилитационных хирургических мероприятий, выбора конструкционных материалов, технологии расчета и создания оптимальных конструкций лечебно-профилактических аппаратов и эктопротезов, вопросами экономической доступности такой реабилитации, отсутствием социального и юридического сопровождения.

Возникновение профессиональных рисков на этапах лечения онкостоматологических пациентов связаны с особенностями лечебного регламента, сложностями проведения хирургических челюстно-лицевых вмешательств, границами возможностей реконструктивно-пластических операщий, зависят от полноты используемого диагностического ресурса и формирования персонализированного протокола ведения пациента, включающего планирование и реализацию хирургического и ортопедического этапов, прогнозирования исходов, профилактики возможных осложнений с использованием современных цифровых технологий [Задеренко и др., 2010; Пивоваров и др., 2014; Назарян и др., 2016; Tariq Aziz et al., 2003; Palousek et al., 2014].

Медико-технологическая группа профессиональных рисков (сложность и многоэтапность лечебно-реабилитационных мероприятий).

Подавляющее большинство случаев рака рта и носоглотки - это карциномы плоского эпителия слизистой оболочки, достаточно часто встречаемый вид опухоли. Протокол лечения включает хирургическую операџию, лучевую и системную противораковую терапию, которые применяются в отдельности или в сочетании. Несмотря на высокую эффективность методов лечения пациентов с опухолями головы и шеи, наблюдаются различные осложнения, связанные с оперативными хирургическими методиками и технологиями реконструктивно-восстановительного лечения. Послеоперационное осложнение - это ухудшение состояния пациента, возникающее во время операции или в послеоперационный период. Есть сообщения о высокой частоте осложнений, полученных в ряде операций по удалению опухолей лица, челюстей, органов и тканей рта и ротоглотки [Задеренко и др., 2010; Кулаков и др., 2012; Дробышев и др., 2014].

Осложнения могут быть результатом действия одновременно нескольких факторов, но основные из них относятся к пациенту, специфике новообразования и лечению. Фактоpы, связанные непосредственно с пациентом и обусловленые его возрастом (чем старше, тем вероятность осложнений выше), низкими показателями общего состояния, сопутствующими заболеваниями (ишемическая болезнь сердца, болезнь органов дыхания, сахарный диабет), курением и чрезмерным употребление алкоголя, плохим питанием и др. Факторы, относящиеся к опухоли - это часто поздние стадии заболевания, агрессивные опухоли. Касательно лечения - это факторы, связанные со сложностью хирургической операции (т. е. длительностью вмешательства), необходимостью реконструкции, проводимого ранее хирургического лечения, необходимость в лучевой и химиотерапии. Последствия осложнений разной степени значимости могут быть связаны с угрозой жизни 
[Нуриева, Филимонова, 2008; Асташина, 2009; Вербо, Крайтор, 2018], увеличением времени пребывания в больнице, продлевают страдания пациента и отрицательно сказываются на его качестве жизни (КЖ); необходимость в дальнейшем лечении, увеличение экономической составляющей лечения, что в совокупности может стать причиной неблагоприятного исхода [Леонтьев, 2010; Давудов, Рагимов, 2017]. Небольшие осложнения: угрозы для жизни может и не быть, но дополнительные операции или длительное пребывание пациента в больнице могут оказаться необходимыми. Тем не менее они отрицательно сказываются на его состоянии и могут способствовать развитию серьезных психических проблем [Арутюнов, 2012; Шанидзе, 2019].

Во время хирургического вмешательства и при выполнении забора лоскута для реконструкции возможно повреждение различных нервов:

- диафрагмального нерва: деинервированная диафрагма может привести к нарушению функции легких и повышенному риску возникновения инфекции;

- симпатического ствола: синдром Горнера;

- добавочного нерва / шейного сплетения;

- краевой ветви лицевого нерва: парез в области нижней губы (временно или постоянно) обычно приводит к нарушению эстетики лица, но значительно не влияет на функцию;

- верхнего гортанного нерва: ослабленный голос [Решетов, 2016; Kerawala et al., 2000].

При замещении дефектов после удаления опухоли и операции на путях лимфотока возможен некроз и отторжение лоскута, поэтому они должны быть под наблюдением в период, непосредственно следующий за операцией. Такая врачебная тактика позволяет ранее выявить проблемы с кровообращением и таким образом повысить вероятность благоприятного исхода. Меры по восстановлению жизнеспособности лоскута включают его реанимацию, за которой следует немедленное обследование с целью установления причины нарушения кровотока. Лечение продолжается в течение периода, необходимого для восстановления коллатерального кровоснабжения. При необходимости проводится реоперация, при некрозе лоскута - удаление лоскута [Задеренко и др., 2010; Дробышев и др., 2014; Решетов, 2016; Харазян и др., 2019].

При злокачественном поражении основания языка, дна полости рта, нижней челюсти и неба нарушение речи будет зависеть от локализации и размеров опухоли, мобильности сохранившейся части языка и других органов рта, наличия зубов, а также метода реконструкции. Любое изменение физиологии и анатомии системы воспроизведения речи, вызванное раком органов и мягких тканей рта и его последующим лечением, может привести к дисфонии (нарушение воспроизведения голоса), дизартрии (любая слабость, медлительность или изменение координации при воспроизведении речи), нарушению речи, подобно нарушению глотательной функции, возникновению проблем в общении, психологическому взаимодействию и ухудшению качества жизни. Значительные нарушения речи часто связаны с крупными опухолями, ограничением или отсутствием движения в сохранившейся части языка, нарушениями функции ротового сфинктера или отсутствием зубов - это факторы, приводящие к нарушению артикуляции нижней челюсти. Опухоли в основании языка или на мягком небе могут привести к гнусавости, выходу пищи или жидкости из носа, сложностям при воспроизведении взрывных звуков. Ксеростомия, вызванная лучевой терапией, может усугубить речевые проблемы. Слух может нарушиться при воспалении слухового канала, скоплении ушной серы, отите среднего уха, фиброзе и нервно-мышечных дисфункциях [Дмитриева, Нуриева, 2014; Казанцев и др., 2016; Forbes, 1997].

Эффект, который хирургическое вмешательство оказывает на глотание, зависит от локализации, размера участка резекции, метода реконструкции или потери функционирования черепных нервов. Проблемы с глотанием после операции чаще возникают при уже существующем до начала лечения нарушении глотательной функции, крупном участке 
резекции, локализации опухоли в дистальных отделах (например, в корне языка, на мягком небе), сопутствующих заболеваниях, реконструкции, особенно при большом размере лоскута, комбинированном лечении (например, вспомогательной лучевой терапии). Проведение глоссэктомии должно осуществляться с сохранением двигательной активности у оставшейся части языка. У пациентов основными проблемами, возникающими после операции, являются нарушения функции жевания, так как пищевой комок частично остается во рту (дисфагия), возникает риск аспирации (проникновение еды/жидкости через дыхательное горло в легкие) [Арутюнов, 2012; Решетов, 2016]. В тяжелых случаях введение трахеостомической трубки может привести к ухудшению дисфагии [Нуриева, Филимонова, 2008; Харазян и др., 2008]. Аспирация может быть клинически видимой, или о ее наличии можно судить по косвенным данным. Тем не менее встречаются случаи бессимптомной аспирации, и вопрос о том, следует ли ограничивать пероральный прием пищи или нет, остается открытым.

По данным ВОЗ, 70-75 \% онкологических больных нуждаются в проведении лучевой терапии. При этом лучевая нагрузка хорошо переносится, на ранних стадиях способствует стойкому излечению с сохранением функции органа-мишени благодаря избирательному дозированию, так как может быть радикальной, паллиативной и успешной в комбинации с хирургией. В неоперабельных случаях паллиативная лучевая терапия весьма эффективна как самостоятельный вид лечения. Однако при этом остается проблемой довольно высокая частота и тяжесть осложнений [Дробышев и др., 2014; Forbes, 1997; Kerawala, Newlands, 2010].

Области воздействия и доза при лучевой терапии зависят от ряда факторов и требуют тщательного планирования и расчетов. Осложнения и побочные эффекты лучевой терапии немедленного действия (проявления) - это мукозит, эритема или образование язв на коже, потеря вкуса, нарушение питания и потеря веса, кровотечение, инфекция, лимфедема. Отсроченные осложнения проявляются в виде фистулы, нарушения процесса заживления, лучевого некроза кости, нарушения глотательной функции, нарушения речи и вкусовой чувствительности, ксеростомии и лучевого кариеса, подверженности зубному кариесу и заболеваниям пародонта, выпадения волос, атрофии кожи, телеангиэктазии и изменения цвета волос (гипопигментации), опухолей, вызванных облучением, невропатии, катаракты хрусталика, гипотиреоза, например, билатерального иссечения шеи и вспомогательной лучевой терапии, фиброза [Дмитриева, Нуриева, 2014; Казанцев и др., 2016; Решетов, 2016]. Частым стоматологическим осложнением подобной терапии является лучевое поражение зубов [Дмитриева, Нуриева, 2014]. Развитие лучевого некроза сохранившихся зубов на верхней и нижней челюстях / фрагментах челюстей происходит в сроки до 6 месяцев после завершения лучевой терапии. При этом на фоне отсутствия боли в первые 3 месяца процесс протекает с развитием гиперестезии твёрдых тканей зубов с последующим асептическим некрозом пульпы зубов и развитием периапикальных осложнений в виде кист и гранулём, требующих удаления зубов. Наряду с этим проявляется патологическая реакция опорных тканей протезного ложа на ортопедические конструкции в первые 6 месяцев после окончания лучевой терапии в результате развития лучевого радиомукозита. Проявления лучевых поражений органов рта начинаются постепенно в виде гиперемии, отечности, сухости слизистой щек, мягкого неба, дна полости рта, появления очагов десквамации и эрозий в зоне облучения. Пораженные участки могут напоминать очаги лейкоплакии и плоского лишая. При увеличении дозы облучения ороговевший эпителий слизистой оболочки покрывается некротическим налетом, образуется очаговый радиомукозит, который переходит в сливной пленчатый радиомукозит. При дистанционном облучении поражаются слюнные железы. Процесс начинается с повышенного слюнооделения (3-5 дней), которое быстро сменяется сухостью рта вплоть до полной ксеростомии, не поддающейся стимуляции. На этом фоне развивается катаральный, а затем язвенный гингивит, который трансформируется в пародонтит. На слизистой оболочке преддверия рта появляются эрозии, переходящие в афты. Язык становится сухим и шероховатым. 
У пациента возникают нарушения вкусового распознавания, извращение вкуса и в последующем его потеря. Нередки глоссалгия и глоссит, которые сопровождаются трещинами, налетом и отеком языка [Кулаков и др., 2012; Казанцев и др., 2016].

Еще более тяжелое осложнение, возникающее после лучевой терапии как с хирургической операцией, так и без него, - это прогрессирующий остеонекроз опорных тканей протезного ложа, протекающий с секвестрацией фрагментов челюсти. Частота распространенности остеорадионекроза варьируется в широких пределах 1-30\%. Более часто он развивается в интервале 5-15\%, чаще на нижней челюсти в области тела и составляет 2-22\%. На верхней челюсти или каких-либо других костях головы и шеи остеорадионекротические процессы возникают гораздо реже. Остеорадионекроз костей лицевого отдела черепа приводит к нарушению акта жевания, глотания из-за сбоя в артикуляции нижней челюсти, обусловленной мышечной дисфункцией.

Возникновение и развитие остеорадионекроза в основном зависит от размера и топографии новообразования, дозы облучения и типа хирургической операции, наличия инфекции, иммунодефицита, недостаточного питания. Остеорадионекроз, будучи полиэтиологическим заболеванием, формируется и зависит от ряда факторов: интенсивности ионизирующего излучения, степени травматического повреждения нижней челюсти, наличия и вида микробных ассоциаций. Из-за анатомических особенностей нижней челюсти, обусловленных ее конфигурацией и сосудистым питанием, в отличие от других костей лицевого скелета, она в большей степени подвержена отрицательным эффектам радиотерапии. Причиной возникновения и развития радионекроза является облитерация нижнеальвеолярной артерии в сочетании с функциональной недостаточностью лицевой артерии, нарушение остеобласто-остеоклистического динамического равновесия в облученной кости [Вербо, Крайтор, 2018]. Конечный результат остеорадионекроза - это патологический перелом челюсти после хирургии и лучевой терапии с последующим протезированием зубочелюстным или челюстным протезами [Дробышев и др., 2014].

В случае неполного клинического эффекта лучевой терапии возможно рецидивирование и продолженный рост опухоли в зоне дефекта или распространение опухолевидного образования на ранее не изменённые анатомические области [Кулаков и др., 2012]. В результате лучевой терапии и/или предшествующего хирургического лечения развиваются фиброзные изменения в тканях-мишенях, что затрудняет формирование персонализированного протокола врачебной тактики ведения этой категории больных. Частота рецидива составляет 25-50\%. Осложнения связаны со сложностями восстановления речи и акта глотания. Прогноз онкозаболевания и эффективность лечения зависят от ранней диагностики рецидивов, которые успешно выявляются с помощью современной цифровой лучевой аппаратуры: КТ, МРТ, ПЭТ, ПЭТ с таллием 201 [Задеренко и др., 2010].

Наилучшие результаты химиолучевого лечения регионарных метастазов достигаются при опухолях подвижной части языка, передних отделов дна полости рта и всех отделов ротоглотки, а также при смещаемых регионарных метастазах, соответствующих индексу N1. Более высокая выживаемость отмечена при экзофитной и язвенной формах роста опухоли [Айдарбекова и др., 2006].

Осложнения после химиотерапии включают: немедленное действие (тяжелые мукозиты, тошнота и рвота, нарушение питания, потеря веса, диарея, некроз мягких тканей, кровотечение, облысение, нейротоксичность, иммуносупрессия, сепсис, нейтропения, тромбоцитопения, функциональная недостаточность многих органов) и поздние осложнения (нефропатия, кардиомиопатия, фиброз легких, ототоксичность, периферийная невропатия). Роль химиотерапии в лечении злокачественных новообразований ротоглотки остается спорной. Чаще всего курс лечения состоит из сочетания лекарств, основанных на платине, флюороурациле, метотрексате или более новых таксанах, и в некоторых случаях на терапии моноклональными антителами, например, цетуксимабом. Нет данных о том, что любой из существующих курсов столь же эффективен, что и отдельное лечение. Также возможно возникновение остеонекроза челюстей на фоне системной химиотерапии, 
приводящего к значительным дефектам, нарушению целостности придаточных пазух носа и непрерывности нижней челюсти [Дробышев и др., 2014; Forbes, 1997].

При распространении опухоли на мягкие ткани, кожу и жевательные мышцы возникают осложнения в виде «прорезывания» эндопротеза, замещающего дефект челюсти, через слизистую оболочку рта или через кожные покровы. Осложнение в виде прорезывания пластины через кожу возможно в результате значительного истончения кожножирового щечного лоскута во время резекции и последующего проведения лучевой терапии. Возможно развитие некроза кожно-мышечного лоскута, спазма мышц жевательной мускулатуры и смещения образовавшихся пострезекционных фрагментов нижней челюсти [Кулаков и др., 2012].

Послеоперационные дефекты лица как средней, так и нижней зоны, как правило, замещаются лицевыми протезами (эпитезами), которые изготавливаются из силиконовых материалов медицинского назначения, вулканизируемых при комнатной температуре. Окрашивание осуществляется методом двойного пигментирования (методики внутреннего и наружного окрашивания силиконового эпитеза).

Важнейшими являются три параметра эстетического восприятия лицевого эпитеза. Первый параметр - выбор метода окрашивания силикона зачастую определяет степень эстетического восприятия искусственно воссозданного органа в контексте визуализации лица [Tariq Aziz et al., 2003]. Однако правильный подбор цвета и оттенков и их реализация при протезировании дефектов лица является не единственным критерием эстетического восприятия.

Bторым параметром является максимально идентичная репродукция парного органа лица (ушной раковины, глазного яблока, орбиты), мульти-органных сегментов лица, в частности носа или целой нижней зоны лица (челюстно-подбородочного сегмента). Для этих целей применяются цифровые технологии прототипирования отсутствующего органа на основе КТ снимков [Palousek et al., 2014]. Но иногда при воссоздании парных зон лица применяются традиционные технологии аналоговой восковой репродукции органов, с дальнейшей их заменой силиконовым материалом внутреннего окрашивания. При репродукции контуров и форм эпитеза на уровне воскового аналога учитывается его максимально точное краевое прилегание по периметру дефекта для имитации незаметного пограничного перехода структур эпитеза на кожные покровы по периметру протезного ложа. Утонченности краев эпитеза обращается максимальное внимание для обеспечения незаметности демаркационных линий при ношении пациентом эпитеза. Для надежного камуфлирования периметра границ перехода от эпитеза к кожным покровам часто используется краевой специальный адгезив, обеспечивающий плотную фиксацию лицевого эпитеза к мягким тканям протезного ложа. Иногда для этой цели бывает достаточным покрытие переходной зоны эпитеза вазелином по периметру, что придает силикону прозрачность и слияние с кожными покровами [Buzayan et al., 2013].

Третьим параметром является правильный выбор метода ретенции эпитеза на протезном ложе органо-дефицитного участка, обеспечивающего его надежную фиксацию. В настоящее время существуют разные методы ретенции эпитезов лица. Выбор метода ретенции при протезировании дефектов лица зависит от патогенетических аспектов образования послеоперационного дефекта. При онкологическом генезе дефекта учитывается фактор злокачественности опухолевого процесса, возможность его рецидива в зоне протезного ложа либо в сопредельных тканях. В связи с этим необходим мониторинг поведения тканевого сегмента операционного ложа после операционной радиационной терапии и т. д. [Решетов, 2016].

Важным фактором выбора ретенционного механизма является размер дефекта и протяженность его границ в функциональных зонах, находящихся в двигательной активности. Немаловажными по значению факторами, определяющими метод ретенции, являются этиология дефекта (пост-онкологический либо врожденный) и возраст пациента. В любом случае выбранный ретенционный метод должен обеспечивать стабильное нахож- 
дение эпитеза на протезном ложе как в состоянии покоя, так и во время функционирования. Надежная ретенция и, соответственно, стабилизация лицевого эпитеза обеспечивают высокие эстетико-функциональные показатели выбранного метода ортопедической реабилитации дефектов средней и нижней зон лица, комбинированных дефектов челюстнолицевой области разного генеза [Назарян и др., 2016; Назарян и др., 2017, Решетов, 2016].

Существует 2 основных метода ретенции лицевых эпитезов:

a) ретенция с применением адгезивных систем на основе силиконов или воднорастворимых эмульсий;

б) ретенция с применением магнитных или балочно-замковых систем с опорой на краниальных имплантатах.

Еще одна тривиальная ретенционная система, предназначенная для ретенции эпитезов лица, - анатомо-механическая (с применением естественных анатомических поднутрений протезного ложа и комбинированием механическими креплениями (очковые оправы), в современных конструкциях почти не применяется [Назарян и др., 2016].

При применении адгезионных систем основными рисками возможных осложнений является микробная контаминация прилегающих краев силиконового эпитеза из-за трудно очищающихся краев эпитеза. Предыдущие слои адгезива часто не полностью удаляются, и с каждыми последующими новыми слоями адгезива гигиенический статус самого эпитеза и протезного ложа ухудшаются. Кроме того, наслоение адгезива нарушает плотное прилегание эпитеза на протезном ложе. Ситуация меняется при применении специальных растворителей клеевых основ [Давудов, Рагимов, 2017].

При применении ретенционных систем с опорой на краниальные имплантаты удается надежно зафиксировать объемные силиконовые эпитезы средней зоны лица, особенно при их комбинации с цельнолитыми пост-резекционными обтураторами. Сильные магнитные системы и балочно-замковые конструкции в комбинации с транс-скуловыми имплантационными системами позволяют надежно фиксировать объемные ортопедические реконструкции при больших послеоперационных дефектах средней и нижней зон лица. Применение этих технологий создает возможность одноэтапной пост-онкологической реабилитации с одномоментным удалением опухоли, внедрением транс-скуловых имплантатов и немедленной загрузкой их несъемным пост-резекционным обтуратором и лицевым эпитезом [Назарян и др., 2017].

Таким образом, вместо применения трехэтапной послеоперационной ортопедической реабилитационной схемы удается комбинировать хирургическое удаление опухоли с воссозданием протезного ложа, создать фиксацию с опорой на краниальные имплантаты с немедленной нагрузкой эпитезом лица и обтуратором верхней челюсти. Риски, связанные с немедленной нагрузкой экстраоральных имплантатов, сводятся к минимуму с применением длинных скуловых онко-имплантатов системы Бранемарк с первичной стабилизацией и торком $80 \mathrm{~N} / \mathrm{cm}$., что позволяет их применить также при дефиците костных структур, при наличии объемных дефектов челюсти и лица [Назарян и др., 2016].

Возможна фиксация лицевого эпитеза с применением экстраоральных имплантатов в области надбровной дуги, орбиты, либо сосцевидного отростка, соответственно, для фиксации ушной раковины. Рекомендуется применять ультракороткие экстраоральные имплантационные системы с глубиной погружения 4-6 мм, ориентируясь по толщине костей лицевого черепа с расположением на них магнитных ретенционных систем. Основным риском при применении данных имплантатно-магнитных систем является возникновение периимплантита, который является результатом сложного «гигиенического статуса» кератинизированных кожных покровов вокруг ультракоротких имплантатов [Николаева и др., 2011].

Для предупреждения данных осложнений рекомендуется применять технологию максимальной мягкотканой редукции протезного ложа, включая зону вокруг имплантата. Важно максимально удалить подкожную жировую клетчатку с волосяными фолликулами, жировыми и потовыми железами в области имплантатов, что значительно уменьшает риск 
возникновения периимплантита, безусловно, при соблюдении пациентом ежедневных гигиенических процедур [Николаева и др., 2011; Назарян и др., 2017; Харазян и др., 2019].

Развитие патологических изменений кожных покровов вокруг экстраоральных имплантатов возможно в результате неудовлетворительной гигиены, что сопряжено с проблемами фиксации эктопротеза и жалобами пациента. Успех челюстно-лицевого ортопедического лечения в значительной мере зависит от способа и надёжности фиксации замещающего протеза. При этом способ фиксации не должен вызывать дискомфорта у пациента или раздражать ткани, с которыми конструкция контактирует. По мнению М.М. Давудова и Ч.Р. Рагимова [Давудов, Рагимов, 2017], основными методами фиксации замещающих протезов являются клеи-адгезивы, механические приспособления, анатомические условия, когда используются ретенционные контуры, существующие на участке деформации, внеротовые имплантаты для фиксации лицевого протеза.

Послеоперационные дефекты лица и челюстей обезображивают пациента, и, как было сказано ранее, методами реконструктивной и пластической хирургии не всегда возможно достижение приемлемого косметического эффекта. В связи с этим назначение конструкций челюстных протезов и эпитезов не только в замещении послеоперационного дефекта, но и утраченных мягких тканей, а это мышцы жевательной мускулатуры, губы, орбита, нос, высота нижнего отдела лица. Таким образом, такие протезы должны отвечать требованиям привлекательности, отвечать индивидуальным потребностям пациента, что весьма затруднительно и не всегда возможно [Харазян и др., 2008; Назарян и др., 2016].

Как правило, высокий функциональный и эстетический результат лечения достигается при небольших дефектах мягких тканей лица при правильном выборе конструкционных материалов, из которых изготавливается челюстной протез и эпитез. Другим важным аспектом является профессиональное умение зубного техника выполнять скульптурное моделирование, подбирать цвет для базовой окраски, производить индивидуализацию лицевого эпитеза. Последний в максимальной мере должен имитировать цвет кожи лица, обладать достаточной прочностью и износостойкостью, обеспечивать комфортность при пользовании. Только благодаря всем этим мероприятиям возможно создать высоко эстетичный протез, с успехом конкурирующий с реконструкциями пластической хирургии [Харазян и др., 2008; Арутюнов, 2012; Есиркепов, 2014].

Зубочелюстные и челюстные протезы чаще всего по конструктивным характеристикам представляют из себя пластиночный съемный протез из полиметилметакрилата (ПММА). Данный факт связан с простотой технологии создания таких конструкций и экономической составляющей [Нуриева, Филимонова, 2008; Кравцов, 2012; Пивоваров и др., 2014]. К недостаткам относится подверженность частым поломкам, что связывают с недостаточной прочностью базисных пластмасс, конструктивными особенностями, т. к. протезы ломаются в «типичном» для съемных пластиночных конструкций месте, клинико-анатомические особенности протезного ложа и поля, нарушения технологического регламента, а сегодня, с появлением цифровых CAD/CAM систем, установлена необходимость обоснованного выбора технологии [Лебеденко и др., 2010; Пивоваров и др., 2014; Арутюнов и др., 2020; Palousek, et al., 2014].

Среди распространенных функциональных осложнений следует отметить нарушение ретенции и стабилизации протеза, его сбрасывание во время функциональной нагрузки вследствие отсутствия адекватного функционального оформления краёв базиса, а также ущемление подвижной слизистой оболочки протезного ложа под ним, особенно при наличии аутотрансплантата [Козицына и др., 2005; Кравцов, 2012; Кулаков и др., 2012; Бакуринских и др., 2015].

После обширной резекции на лице с вовлечением верхней челюсти и нижнего края орбиты дефект замещают комбинированным протезом. Такая разнотолщинная ортопедическая конструкция создает напряжения, которые инициируют процессы разрушения [Лебеденко и др., 2010; Арутюнов, 2012]. В таких случаях рекомендуют базис армировать металлической сеткой [Карасева, 2014]. Однако научно обоснована несостоятельность этой 
техники армирования [Афанасьева, 2016]. Такие устоявшиеся в клинической практике «аксиомы» пополняют группу профессиональных рисков врача-стоматолога-ортопеда.

Эффективность зубочелюстного аппарата в первую очередь определяет степень его фиксации, что практически всегда проблематично из-за анатомо-топографических особенностей дефекта, но крайне необходимо для предупреждения быстропрогрессирующего формирования вторичных зубочелюстных деформаций из-за отсутствия окклюзии между сохранившимися зубными рядами, конвергенцией фрагментов челюстей, наличия резецированных мышц жевательной мускулатуры, тризма и рубцовых образований [Макаревич, 2009].

Срок годности съемных эктопротезов зависит от механического износа, деструкции полимера, особенностей ухода и гигиены. Как правило, их жизненный цикл ограничен 2-4 годами. В течение этого времени посредством ремонта (перебазировки базиса протеза) улучшаются фиксация конструкции и разобщение соустья между полостями рта, носа и верхнечелюстных пазух [Лебеденко и др., 2010; Арутюнов, 2012; Решетов, 2016; Шанидзе, 2019].

Дентальная имплантация стала частью клинической практики в реабилитации при челюстно-лицевом протезировании и сопряжена с определенными профессиональными рисками [Блинова и др., 2018]. Несмотря на высокий уровень успеха в раннем послеоперационном периоде, одним из наиболее частых отдалённых осложнений дентальной имплантации является периимплантит [Решетов, 2016]. Исследованиями ряда авторов установлен факт неизбежности периимплантита по истечении 5-10 лет у 10 \% установленных дентальных имплантатов. Как правило, периимплантит обусловлен гематомой над заглушкой с последующим ее нагноением, нарушениями протокола атравматичного формирования костного ложа, травмирующим наложением швов на рану, вызывающим ишемию ее краев, неправильным выбором конструкции протеза, окклюзионными интервенциями, некачественной индивидуальной гигиеной рта, изменением статуса общего и местного иммунитета, возникновением или обострением коморбидных заболеваний. Наряду с этим важен контроль и мониторинг состояния остеинтеграции имплантатов посредством частотно-резонансного тестирования внутрикостных имплантатов для обоснованного непосредственного их нагружения [Маркин и др., 2006; Ерошин и др., 2009; Назарян и др., 2016]. Анализ структуры этих осложнений указывает, что они входят в группу профессионального риска и высокой ответственности врача-стоматолога.

Непреложной причиной развития периимплантита являются микробные ассоциации, формирующие биопленку [Пивоваров и др., 2014]. Биопленка, которая появляется на обнаженных витках имплантата в случае отсутствия адекватного десневого прикрепления, порождает большее видовое разнообразие прокариот [Блинова и др., 2018]. У пациентов с развившимися воспалительными процессами в тканях, окружающих имплантат, с высокой частотой выявляют потенциально пародонтопатогенные бактерии II порядка (P.micra, F.nucleatum, C.rectus и E.nodatum), а также I порядка (T.forsythia и P.gingivalis) [Николаева и др., 2011].

Экспериментально установлено, что в сочетании с определенными видами бактерий (S.sanguinis, S.mutans) увеличивается пропорция и площадь гифов Candida albicans, что свидетельствует об усилении ее вирулентных свойств [Блинова и др., 2018].

Применение дентальных имплантатов ограничивается качеством и объемом имеющейся костной ткани челюстей. Для расширения показаний дентальной имплантации с успехом используется костная пластика, эффективность которой для реконструкции атрофированных челюстей составляет 72-75\%. При этом наиболее частая проблема - это присоединение инфекции в области трансплантата, которая в 19-21 \% случаев приводит к частичной или полной секвестрации аутотрансплантата.

Принцип «один имплантат - один аутотрансплантат» при тотальной реконструкции альвеолярного отростка/ части челюсти отчасти может снизить риск полной неудачи лечения. В этом случае возможна повторная операция на ограниченном сегменте челюсти и 
не рекомендуется при использовании цельного аутотрансплантата, локальные осложнения в области которого чаще всего приводят к удалению всего трансплантата, сводят на нет результат большой, сложной операции и длительного лечения [Параскевич и др., 2005].

В концепцию современного остеосинтеза и трансплантации кости входит принцип максимально стабильного соединения костных фрагментов с достижением наиболее плотного контакта между ними и необходимой компрессией для исключения непредсказуемого развития репаративной регенерации. Основным фактором успешного остеосинтеза является механическая нагрузка. Отсутствие или ее резкое уменьшение приводит к снижению интенсивности репаративных процессов в костной ткани. Костные фрагменты после репозиции должны быть прочно зафиксированы, чтобы исключить травму регенерата. Жесткая фиксация создает микродеформацию фрагментов и регенерата без повреждения остеогенных структур, что является адекватным условием оптимального репаративного остеогенеза. В хирургической практике наиболее популярны накостные пластины и винты [Кобзева и др., 2013].

Помимо этого, в результате неудовлетворительной гигиены рта после хирургического вмешательства, лучевой терапии и последующего зубочелюстного протезирования, возможно развитие патологических изменений слизистой оболочки вокруг опорных дентальных имплантатов и, как следствие, их потеря, а иногда - остеонекроз и секвестрация значительных фрагментов костной ткани [Дробышев и др., 2014].

В настоящее время социум делает акцент на физическую привлекательность, при этом лицо занимает центральное место в социальном взаимодействии. Лечение рака рта, как правило, ведет к искажению лица и функциональным изменениям, например, нарушению речи, питания, глотания и потере способности к невербальному общению вследствие нервного паралича. Это может оказать большое влияние на пациента, изменяя его представления о своем теле, понижая его самооценку и провоцируя негативные ощущения (депрессия, чувство одиночества, суицидальные мысли). Искаженные черты лица или неспособность к нормальному общению могут привести к явной и даже грубой реакции со стороны пациента. Как следствие, пациент может начать чувствовать себя изгоем. Хроническая боль только увеличит элемент депрессии. Пациенты могут стать более чувствительными к побочным эффектам, агрессивно реагировать на вещи и искать прибежище, избегая социального общения, злоупотреблять алкоголем или наркотиками. Рак рта и его лечение оказывают сильное воздействие на пациентов. Они могут страдать от физических, функциональных, психологических проблем и проблем, связанных с косметическими дефектами. Традиционно основной целью лечения является контроль болезни и повышение выживаемости. Отзывы и анкетные бланки, заполненные клиницистами, зачастую недооценивают проблемы пациента и могут не соответствовать его точке зрения [Михайлова и др., 1997; Арутюнов, 2012; Шанидзе, 2019].

Хотя общая выживаемость не теряет своей значимости, результат лечения все в большей степени оценивается относительно качества жизни. Это широко используемое понятие, хорошо знакомое обычным людям, часто подразумевает чувство благополучия и связано у пациента с чувством удовлетворения. Сложно дать определение тому, что такое качество жизни, и лучше всего рассматривать этот термин как многомерное понятие. Даже в отношении здоровья его определение остается дискуссионным. В дополнение к таким областям, как физическое, функциональное, психологическое и социальное функционирование, в это понятие включают также экономическую, финансовую, профессиональную сферы, а также сферу семейной жизни (включая сексуальность) [Асташина, 2009; Макаревич, 2009].

Предложено множество методов по оценке качества жизни. Идеального опросника в этом отношении не существует. Выбранный опросник должен быть приемлемым, утвержденным, надежным, практичным в использовании и должен позволять ответить на задаваемые вопросы (т. е. соответствовать целям) [Михайлова и др., 1997; Асташина, 2009; Макаревич, 2009; Арутюнов, 2012; Шанидзе, 2019]. 


\section{Заключение}

На данный момент отмечается факт, что диагностика злокачественных опухолей стала осуществляться на более ранних этапах и выживаемость больных повысилась. В то же время современные методы лечения остаются крайне агрессивными, порой терапия заканчивается всевозможными масштабными нарушениями деятельности организма, работоспособность человек часто утрачивает. Прогноз лечения и жизни пациента затруднителен неясностью клинического прогноза, высокой степенью риска возникновения рецидива и метастазирования, что повышает профессиональные риски врачей, участвующих в реабилитации онкобольных.

Полное выздоровление пациентов этой категории в настоящее время практически невозможно. Основной целью медицинской реабилитации онкобольного является выбор наиболее эффективного органосохраняющего хирургического и химиолучевого лечения, планирования объема и вида протезирования в структуре реконструктивновосстановительных операций с использованием современных цифровых технологий.

Наряду с этим необходимо учитывать, что онкологическое заболевание, как правило, сопряжено с развитием психогенных реакций, степень выраженности и динамичность развития которых оказывает несомненное влияние на число послеоперационных осложнений и эффективность последующего восстановительного лечения. Поэтому реабилитация должна включать комплекс профессиональных медицинских мероприятий, направленных на восстановление работоспособности, полноценное возвращение в социум.

Таким образом, подводя итоги метаанализа, надо подчеркнуть, что в реабилитации пациентов с опухолями головы и шеи важна последовательность и полнота проводимых организационно-управленческих мероприятий по профилактике, обеспечению протокола лечения современным цифровым диагностическим ресурсом, аппаратным и аппаратурным оснащением, позволяющим челюстно-лицевому хирургу и врачу-стоматологуортопеду в полном объеме реализовать профессиональные компетенции, психологическим и социальным сопровождением с момента постановки диагноза и пожизненно из-за развития пограничных психических расстройств и необходимости рассмотрения широкого круга вопросов (труд, семья, быт, досуг) при социально-трудовой реабилитации.

\section{Список литературы}

1. Айдарбекова А.А., Любаев В.Л., Ткачев С.И., Алиева С.Б., Бржезовский В.Ж. 2006. Эффективность химиолучевой терапии при регионарных метастазах у больных раком слизистой оболочки полости рта и ротоглотки. Вестник РОНЦ им. Н.Н. Блохина РАМН, 17 (1): 7-9.

2. Арутюнов А.С. 2012. Клинико-организационные основы повышения эффективности ортопедической стоматологической реабилитации онкологических больных с приобретенными дефектами верхней челюсти: Дис. ... д-р мед. наук - М., 337 с.

3. Арутюнов А.С., Седракян А.Н., Ахмедов Р.-М.А., Комов Е.В., Арутюнов С.Д. 2009. Повышение эффективности ортопедического лечения онкологических больных с послеоперационными дефектами верхней челюсти. Российский стоматологический журнал. 3: 24-27.

4. Арутюнов С.Д., Никитин И.С., Грачев Д.И., Никитин А.Д. 2020. Математическое моделирование жевательной нагрузки на базис съемного протеза при полном отсутствии зубов. XXXI Международная инновационная конференция молодых ученых и студентов (МИКМУС-2019): Сборник трудов конференции (Москва, 4-6 декабря 2019). - М.: ИМАШ РАН. С. 372-375.

5. Асташина Н.Б. 2009. Комплексное лечение и реабилитация пациентов с приобретенными дефектами челюстей. Экспериментально-клиническое исследование: Автореф. дис. ... д-ра мед. наук: 14.00.21. Пермь, 46 с.

6. Афанасьева В.В. 2016. Повышение эффективности реставрации съемных пластиночных зубных протезов после поломки. Дисс. ... кандидата медицинских наук. М., 163 с.

7. Бакуринских А.А., Ларионов Л.П., Мирсаев Т.Д., Жолудев С.Е., Хонина Т.Г., Шадрина Е.В., Иваненко М.В., Бакуринских Е.А., Богданова Е.А., Сабирзянов Н.А., Бакуринских А.Б., Филиппова Е.В. 2015. Средство для фиксации съемных зубных протезов, профилактики и лечения поражений слизистой оболочки полости рта на основе кремний титанорганического глицерогид- 
рогеля, содержащее бифидумбактерин и гидроксиапатит. Вестник Уральской медицинской академической науки. 2 (53): 10-15.

8. Блинова А.В., Рюмшин Р.А., Румянцев В.А. 2018. Периимплантит - основное осложнение дентальной имплантации (обзор литературы). Верхневолжанский медицинский журнал. 17 (1): 13-18.

9. Вербо Е.В., Крайтор А.С. 2018. Концепция патогенеза остеорадионекроза челюстей. Head and Neck / Голова и шея. Российское издание. Журнал Общероссийской общественной организации Федерация специалистов по лечению заболеваний головы и шеи. 1: 65-70.

10. Гвоздикова Е.Н. 2017. Особенности тактики лечения оральных мукозитов у онкологических больных на фоне лучевого лечения и/или химиотерапии 14.01.12 - онкология 14.01.14 стоматология / автореф. дисс. ... канд. мед. наук, М., 24 с.

11. Геворкян А.А., Газазян В.В., Терентьев А.В. 2007. Проблемы ортопедического лечения больных с зубочелюстно-лицевыми дефектами и деформациями. Сибирский медицинский журнал (Иркутск). 69 (2): 5-9.

12. Давудов М.М., Рагимов Ч.Р. 2017. Качество жизни пациентов с дефектами верхней и нижней челюстей после онкологических операций полости рта и ортопедической реабилитации. Хирургия. Восточная Европа. 6 (2): 241-248.

13. Дмитриева Е.Ф., Нуриева Н.С. 2014. Лучевой кариес: клиническая картина, вопросы лечения. Проблемы стоматологии. 2: 9-12.

14. Дробышев А.Ю., Заславская Н.А., Волков А.Г., Лежнев Д.А. 2014. Диагностика и лечение остеонекрозов челюстей у больных со злокачественными новообразованиями, получающих терапию антирезорбтивными препаратами (бисфосфонаты, деносумаб) Научно-практический журнал «Медицинский вестник МВД». № 1. Том LXVIII - С. 14-16.

15. Ерошин В.А., Арутюнов С.Д., Арутюнов А.С., Унанян В.Е., Бойко А.В. 2009. Подвижность дентальных имплантатов: приборы и методы диагностики. Российский журнал биомеханики. М., 13-2 (44): 23-37.

16. Есиркепов А. А. 2014. Ортопедическая стоматологическая помощь больным с челюстно-лицевыми дефектами. Вестник Казахского Национального медицинского университета. 2: $142-144$.

17. Задеренко И.А., Дробышев А.Ю., Кропотов М.А., Алиева С.Б., Шишканов А.В., Азизян Р.И. 2010. Варианты замещения дефектов при хирургическом лечении злокачественных опухолей слизистой оболочки щеки. Научно-практический журнал «Вопросы челюстно-лицевой, пластической хирургии, имплантологии и клинической стоматологии» М., 5-6: 43-48.

18. Казанцев М.Е., Галонский В.Г., Казанцева Т.В., Гайлис Д.Я. 2016. Лучевые поражения органов полости рта при лечении злокачественных новообразований челюстно-лицевой области (обзор литературы). Сб.: Сибирский стоматологический форум. Инновационные подходы к образованию, науке и практике в стоматологии. Труды X Всероссийской научно-практической конференции. Главный редактор Алямовский В.В., ответственный редактор Нарыкова С.А. С. 33-35.

19. Каприн А.Д., Старинский В.В., Алексеева Г.С., Балашов П.Ю. 2013. Внедрение порядка оказания медицинской помощи населению по профилю «онкология». Совершенствование структурной и кадровой политики онкологической службы. Вестник РОСЗДРАВНАДЗОРА. 5: 9-13.

20. Каприн А.Д., Старинский В.В., Петрова Г.В. 2017. Состояние онкологической помощи населению России в 2016 году. - М.: МНИОИ им. П.А. Герцена, 23: 6. ISBN 978-5-85502-231-5 https://nmicr.ru/upload/doc/2017/2017_kniga_sostoyanie_onkopomoshi_v_2016.pdf.

21. Карасева В.В. 2014. Профилактика частых переломов пластиночных протезов путем использования армирующей кварцевой сетки. Проблемы стоматологии. 5: 41-44.

22. Кобзева И.В., Дробышев А.Ю., Давыдов Д.В., Дубина Л.Х. 2013. Применение системы резорбируемых пластин и пинов при лечении больных с челюстно-лицевой травмой. Тихоокеанский медицинский журнал. 1 (51): 67-69.

23. Козицына С.И., Михайлов И.В., Антипов В.В. 2005. Особенности протезирования при частичной резекции верхней челюсти. Институт стоматологии. 2 (27): 24-25.

24. Кондратова Н.В. 2016. Риск-менеджмент в медицинской организации: как извлечь пользу из медицинских ошибок. В мире научных открытий. Красноярск, 4 (76): 52-62.

25. Кравцов Д.В. 2012. Клинико-микробиологическое обоснование и оценка эффективности применения зубочелюстных протезов-обтураторов из различных конструкционных материа- 
лов 14.01.14 - Стоматология (медицинские науки) 03.02 .03 - Микробиология (медицинские науки): Автореф. дисс. ... канд. мед. наук, М., 24 с.

26. Кулаков А.А., Чучков В.М., Матякин Е.Г., Романов И.С., Ахундов А.А., Мудунов А.М., Федотенко С.П., Федотов Н.Н., Подвязников С.О., Кропотов М.А., Жарков О.А., Чучков М.В. 2012. Результаты ортопедического лечения онкологических больных с челюстнолицевыми дефектами. Опухоли головы и шеи. 1: 51-55.

27. Лебеденко И.Ю., Чумаченко Е.Н., Янушевич О.О., Арутюнов С.Д., Ибрагимов Т.И., Лосев Ф.Ф., Игнатьева Д.Н., Мальгинов Н.Н. 2010. Применение информационных технологий при планировании лечения в практике ортопедической стоматологии. Российский стоматологический журнал. М., 3: 22-26.

28. Леонтьев В.К. 2010. Страхование профессиональных рисков в стоматологии (опыт стоматологов и страховых компаний). Институт стоматологии. 2 (47): 12-15.

29. Макаревич А.А. 2009. Качество жизни челюстно-лицевых онкологических больных после ортопедической стоматологической реабилитации: Дисс. ... кандидата медицинских наук. M., $168 \mathrm{c}$.

30. Маркин В.А., Олесова В.Н., Арутюнов С.Д., Мушаев И.У., Поздеев А.И., Гарафутдинов Д.М. 2006. Частотно-резонансное тестирование внутрикостных имплантатов на нижней челюсти как метод обоснования их непосредственной нагрузки. Российский стоматологический журнал. 1: 44-46.

31. Михайлова В.В., Панин М., Барденштейн Л.М., Климов Б.А. 1997. Психологическая оценка больных с врожденными и приобретенными челюстно-лицевыми деформациями в до- и послеоперационом периодах. Стоматология.76 (5): 35-39.

32. Назарян Д.Н., Харазян А.Э., Яранцев С.В. 2016. Немедленная нагрузка на краниальных имплантатах для устранения дефектов лица. Анналы пластической, реконструктивной и эстетической хирургии. 1: 90-91.

33. Назарян Д.Н., Яранцев С.В., Харазян А.Э., Черненький М.М. 2017. Имплантация с немедленной нагрузкой в анапластологии. Цифровая стоматология. 6 (1): 80-85.

34. Николаева Е.Н., Чувилкин В.И., Царев В.Н., Панин А.М., Хитаришвили М.В., Царева Т.В. 2011. Экспрессия пародонтопатогенных бактерий I и II порядка у пациентов с периимплантитами. Dental Forum. 4: 10-12.

35. Нуриева Н.С., Филимонова О.И. 2008. Стоматологическая помощь пациентам со злокачественными образованиями полости рта при специализированном лечении. Уральский медицинский журнал. 10 (50): 123-125.

36. Параскевич В.Л., Артюшкевич А.С, Яцкевич О.С. 2005. Методика тотальной реконструкции альвеолярного отростка верхней челюсти. Институт стоматологии. 2 (27): 18-23.

37. Пивоваров А.А., Арутюнов С.Д., Муслов С.А., Раимова Д.Б., Козлов С.С. 2014. Прочностные свойства фрезерованных зубочелюстных протезов из конструкционного стоматологического материала. Современные проблемы науки и образования. 4: 326. URL: http://www.scienceeducation.ru/118-14324 (дата обращения: 15.08.2014).

38. Решетов И.В.. 2016. Опухоли органов головы и шеи. Технологии лечения, реконструкции, реабилитации пациентов: реконструкция тканей. Изд-во ОАО «Тверской полиграфический комбинат», $520 \mathrm{c}$.

39. Соловьева А.М. 2011. Периимплантит: этапы достижения консенсуса в диагностике и лечении. Клиническая стоматология. 1 (57): 50-52.

40. Харазян А.Э., Арутюнов А.С., Лебеденко И.Ю., Арутюнов С.Д. 2008. Эстетическое формирование лицевого протеза при дефектах средней зоны лица. Институт стоматологии. СПб. 3 (40): $42-45$.

41. Харазян А.Э., Назарян Д.Н., Яранцев С.В., Черненький М.М. 2019. Новый способ устранения дефектов нижней зоны лица у соматически отягощенных пациентов. Анналы хирургии, 24 (2): 94-99.

42. Шанидзе 3.Л. 2019. Совершенствование стоматологического ортопедического лечения пациентов с полным отсутствием зубов и послеоперационными дефектами верхней челюсти. Автореф. дисс. ... канд. мед. наук: (14.01.14 - стоматология). М.: ЦНИИС. 24 с.

43. Buzayan M.M. 2013. Prosthetic management of mid-facial defects with magnet-retained silicone prosthesis. Journal of Prosthetics and Orthotics International. 
44. Forbes K. 1997. Palliative care in patients with cancer of the head and neck. Clin. Otolaryngol. 22: 117 . Oxford.

45. Kerawala C., Newlands C. 2010. Oral and Maxillofacial Surgery, Oxford University Press,

46. Palousek D., Rosicky J., Koutny D. 2014. Use of digital technologies in nasal prosthesis manufacturing. Prosthetics and Orthotics International, 38 (2): 171-175.

47. Tariq Aziz, Mark Waters, Robert Jagger, 2003. Analysis of the properties of silicone rubber maxillofacial prosthetic materials. Journal of Dentistry, 31 (1): 67-74.

48. Watkinson J.C., Gaze M.N., Wilson J.A. 2000. Reconstraction. In Stell P.M. and Maran A.G.D., Head and neck surgery, 4th edn, pp. 101-57. Battwerworth - Heinmann, Oxford University Press, Oxford.

\section{References}

1. Ajdarbekova A.A., Ljubaev V.L., Tkachev S.I., Alieva S.B., Brzhezovskij V.Zh. 2006. Jeffektivnost' himioluchevoj terapii pri regionarnyh metastazah u bol'nyh rakom slizistoj obolochki polosti rta i rotoglotki [The effectiveness of chemoradiotherapy for regional metastases in patients with cancer of the oral mucosa and oropharynx]. Vestnik RONC im. N.N. Blohina RAMN, 17 (1): 7-9.

2. Arutjunov A.S. 2012. Kliniko-organizacionnye osnovy povyshenija jeffektivnosti ortopedicheskoj stomatologicheskoj reabilitacii onkologicheskih bol'nyh s priobretennymi defektami verhnej cheljusti [Clinical and organizational basis for improving the effectiveness of orthopedic dental rehabilitation of cancer patients with acquired defects of the upper jaw]. Dis. ... d-r med. nauk - M., $337 \mathrm{~s}$.

3. Arutjunov A.S., Sedrakjan A.N., Ahmedov R.-M.A., Komov E.V., Arutjunov S.D. 2009. Povyshenie jeffektivnosti ortopedicheskogo lechenija onkologicheskih bol'nyh s posleoperacionnymi defektami verhnej cheljusti [Increasing the efficacy of orthopedic treatment of oncological patients with postoperative maxillary defects]. Rossijskij stomatologicheskij zhurnal. 3: 24-27.

4. Arutjunov S.D., Nikitin I.S., Grachev D.I., Nikitin A.D. 2020. Matematicheskoe modelirovanie zhevatel'noj nagruzki na bazis s"emnogo proteza pri polnom otsutstvii zubov [Mathematical modeling of chewing load on the basis of removable prosthesis with the complete absence of teeth]. XXXI Mezhdunarodnaja innovacionnaja konferencija molodyh uchenyh i studentov (MIKMUS-2019): Sbornik trudov konferencii (Moskva, 4-6 dekabrja 2019). - M.: IMASh RAN, C. 372-375.

5. Astashina N.B. 2009. Kompleksnoe lechenie i reabilitacija pacientov s priobretennymi defektami cheljustej. Jeksperimental'no-klinicheskoe issledovanie [Comprehensive treatment and rehabilitation of patients with acquired jaw defects. Experimental clinical trial]. Avtoref. dis. ... d-ra med. nauk: 14.00.21. Perm', 46 s.

6. Afanas'eva V.V. 2016. Povyshenie jeffektivnosti restavracii s"emnyh plasti-nochnyh zubnyh protezov posle polomki [Improving the efficiency of restoration of removable laminar dentures after failure]. Diss. ... kandidata medicinskih nauk. M., $163 \mathrm{s.}$

7. Bakurinskih A.A., Larionov L.P., Mirsaev T.D., Zholudev S.E., Honina T.G., Shadrina E.V., Ivanenko M.V., Bakurinskih E.A., Bogdanova E.A., Sabirzjanov N.A., Bakurinskih A.B., Filippova E.V. 2015. Sredstvo dlja fiksacii s"emnyh zubnyh protezov, profilaktiki i lechenija porazhenij slizistoj obolochki polosti rta na osnove kremnij titanorganicheskogo glicerogidrogelja, soderzhashhee bifidumbakterin i gidroksiapatit [Medicine for fixing dentures, prevention and treatment of lesions of the oral mucosa on the base of organosilicontitanium glycerohydrogel, containing bifidumbacterinum and hydroxyapatite]. Vestnik Ural'skoj medicinskoj akademicheskoj nauki. 2 (53): 10-15.

8. Blinova A.V., Rjumshin R.A., Rumjancev V.A. 2018. Periimplantit - osnovnoe oslozhnenie dental'noj implantacii (obzor literatury) [Periimplantitis - the basic complication of the dental implantation (literature review)]. Verhnevolzhanskij medicinskij zhurnal. 17 (1): 13-18.

9. Verbo E.V., Krajtor A.S. 2018. Koncepcija patogeneza osteoradionekroza cheljustej [Osteoradionecrosis of jaws: pathogenesis conception]. Head and Neck / Golova i sheja. Rossijskoe izdanie. Zhurnal Obshherossijskoj obshhestvennoj organizacii Federacija specialistov po lecheniju zabolevanij golovy i shei. 1: $65-70$.

10. Gvozdikova E.N. 2017. Osobennosti taktiki lechenija oral'nyh mukozitov u onkologicheskih bol'nyh na fone luchevogo lechenija i/ili himioterapii [Features of treatment tactics for oral mucositis in cancer patients with radiation treatment and/or chemotherapy]. 14.01.12 - onkologija 14.01.14 - stomatologija / avtoref. diss. ... kand. med. nauk, M., 24 s. 
11. Gevorkjan A.A., Gazazjan V.V., Terent'ev A.V. 2007. Problemy ortopedicheskogo lechenija bol'nyh s zubocheljustno-licevymi defektami i deformacijami [To the problem of complex rehabilitation of patients with maxillofacial defects]. Sibirskij medicinskij zhurnal (Irkutsk). 69 (2): 5-9.

12. Davudov M.M., Ragimov Ch.R. 2017. Kachestvo zhizni pacientov s defektami verhnej i nizhnej cheljustej posle onkologicheskih operacij polosti rta i ortopedicheskoj reabilitacii [Quality of life in patients with defects of the upper and lower jaws after oncological operations of the oral cavity and orthopedic rehabilitation]. Hirurgija. Vostochnaja Evropa. 6 (2): 241-248.

13. Dmitrieva E.F., Nurieva N.S. 2014. Luchevoj karies: klinicheskaja kartina, voprosy lechenija [Radiation caries: clinical presentation, treatment issues]. Problemy stomatologii. 2: 9-12.

14. Drobyshev A.Ju., Zaslavskaja N.A., Volkov A.G., Lezhnev D.A. 2014. Diagnostika i lechenie osteonekrozov cheljustej u bol'nyh so zlokachestvennymi novoobrazovanijami, poluchajushhih terapiju antirezorbtivnymi preparatami (bisfosfonaty, denosumab) [Pathomorphological characteristics of bisphosphonate osteonecrosis of the jaws]. Nauchno-prakticheskij zhurnal «Medicinskij vestnik MVD» 1. Tom LXVIII - S. 14-16.

15. Eroshin V.A., Arutjunov S.D., Arutjunov A.S., Unanjan V.E., Bojko A.V. 2009. Podvizhnost' dental'nyh implantatov: pribory i metody diagnostiki [Mobility of dental implants: devices and diagnostic methods]. Rossijskij zhurnal biomehaniki. M., 13-2 (44): 23-37.

16. Esirkepov A.A. 2014. Ortopedicheskaja stomatologicheskaja pomoshh' bol'nym s cheljustnolicevymi defektami [Prosthetic dental care to patients with maxilliofacial defects]. Vestnik Kazahskogo Nacional'nogo medicinskogo universiteta. 2: 142-144.

17. Zaderenko I.A., Drobyshev A.Ju., Kropotov M.A., Alieva S.B., Shishkanov A.V., Azizjan R.I. 2010. Varianty zameshhenija defektov pri hirurgicheskom lechenii zlokachestvennyh opuholej slizistoj obolochki shheki [Defect replacement options in the surgical treatment of malignant tumors of the cheek mucosa]. Nauchno-prakticheskij zhurnal «Voprosy cheljustno-licevoj, plasticheskoj hirurgii, implantologii i klinicheskoj stomatologii» M., 5-6: 43-48.

18. Kazancev M.E., Galonskij V.G., Kazanceva T.V., Gajlis D.Ja. 2016. Luchevye porazhenija organov polosti rta pri lechenii zlokachestvennyh novoobrazovanij cheljustno-licevoj oblasti (obzor literatury) [Radiation damage to the oral cavity in the treatment of malignant neoplasms of the maxillofacial region]. Sb.: Sibirskij stomatologicheskij forum. Innovacionnye podhody k obrazovaniju, nauke i praktike v stomatologii. Trudy X Vserossijskoj nauchno-prakticheskoj konferencii. Glavnyj redaktor Aljamovskij V.V., otvetstvennyj redaktor Narykova S.A. S. 33-35.

19. Kaprin A.D., Starinskij V.V., Alekseeva G.S., Balashov P.Ju. 2013. Vnedrenie porjadka okazanija medicinskoj pomoshhi naseleniju po profilju «onkologija» [Introducing procedure for medical care in the area of oncology. Improvement of organizational and staff policy at oncology service]. Sovershenstvovanie strukturnoj i kadrovoj politiki onkologicheskoj sluzhby. Vestnik ROSZDRAVNADZORA. 5: 9-13.

20. Kaprin A.D., Starinskij V.V., Petrova G.V. 2017. Sostojanie onkologicheskoj pomoshhi naseleniju Rossii v 2016 godu [The status of cancer care for the population of Russia in 2016]. - M.: MNIOI im. P.A. Gercena, 23: 6. ISBN 978-5-85502-231-5. https://nmicr.ru/upload/doc/2017/2017_kniga_sostoyanie _onkopomoshi_v_2016.pdf.

21. Karaseva V.V. 2014. Profilaktika chastyh perelomov plastinochnyh protezov putem ispol'zovanija armirujushhej kvarcevoj setki [Prequent fracture prevention through laminar dentures by using reinforcing quartz mesh]. Problemy stomatologii. 5: 41-44.

22. Kobzeva I.V., Drobyshev A.Ju., Davydov D.V., Dubina L.H. 2013. Primenenie sistemy rezorbiruemyh plastin i pinov pri lechenii bol'nyh s cheljustno-licevoj travmoj [The usage of resorbable plates and pins for treating patients with maxillofacial trauma]. Tihookeanskij medicinskij zhurnal. 1 (51): $67-69$.

23. Kozicyna S.I., Mihajlov I.V., Antipov V.V. 2005. Osobennosti protezirovanija pri chastichnoj rezekcii verhnej cheljusti [Features of prosthetics with partial resection of the upper jaw]. Institut stomatologii. 2 (27): 24-25.

24. Kondratova N.V. 2016. Risk-menedzhment v medicinskoj organizacii: kak izvlech' pol'zu iz medicinskih oshibok [Risk management in medical organization: how to find benefit in medical errors]. V mire nauchnyh otkrytij. Krasnojarsk, 4 (76): 52-62.

25. Kravcov D.V. 2012. Kliniko-mikrobiologicheskoe obosnovanie i ocenka jeffektivnosti primenenija zubocheljustnyh protezov-obturatorov iz razlichnyh konstrukcionnyh materialov [Clinical and microbiological substantiation and assessment of the effectiveness of the use of dentition dentures- 
obturators from various structural materials]. 14.01.14 - Stomatologija (medicinskie nauki) 03.02.03 Mikrobiologija (medicinskie nauki): Avtoref. diss. ... kand. med. nauk, M., 24 c.

26. Kulakov A.A., Chuchkov V.M., Matjakin E.G., Romanov I.S., Ahundov A.A., Mudunov A.M., Fedotenko S.P., Fedotov N.N., Podvjaznikov S.O., Kropotov M.A., Zharkov O.A., Chuchkov M.V. 2012. Rezul'taty ortopedicheskogo lechenija onkologicheskih bol'nyh s cheljustnolicevymi defektami [Results of orthopedic treatment in cancer patients with maxillofacial defects]. Opuholi golovy i shei. 1: 51-55.

27. Lebedenko I.Ju., Chumachenko E.N., Janushevich O.O., Arutjunov S.D., Ibragimov T.I., Losev F.F., Ignat'eva D.N., Mal'ginov N.N. 2010. Primenenie informacionnyh tehnologij pri planirovanii lechenija $\mathrm{v}$ praktike ortopedicheskoj stomatologii [The use of information technology in treatment planning in the practice of orthopedic dentistry]. Rossijskij stomatologicheskij zhurnal. M., 3: 22-26.

28. Leont'ev V.K. 2010. Strahovanie professional'nyh riskov v stomatologii (opyt stomatologov i strahovyh kompanij) [Insurance against professional risks in dentistry (from the experience of dentists and Insurance companies]. Institut stomatologii. 2 (47): 12-15.

29. Makarevich A.A. 2009. Kachestvo zhizni cheljustno-licevyh onkologicheskih bol'nyh posle ortopedicheskoj stomatologicheskoj reabilitacii [Quality of life of maxillofacial oncological patients after orthopedic dental rehabilitation]. Diss. ... kandidata medicinskih nauk. M., $168 \mathrm{s.}$

30. Markin V.A., Olesova V.N., Arutjunov S.D., Mushaev I.U., Pozdeev A.I., Garafutdinov D.M. 2006. Chastotno-rezonansnoe testirovanie vnutrikostnyh implantatov na nizhnej cheljusti kak metod obosnovanija ih neposredstvennoj nagruzki [Frequency resonance testing of intraosseous implants in the lower jaw as a method of justifying their immediate load]. Rossijskij stomatologicheskij zhurnal. 1: 44-46.

31. Mihajlova V.V., Panin M., Bardenshtejn L.M., Klimov B.A. 1997. Psihologicheskaja ocenka bol'nyh s vrozhdennymi i priobretennymi cheljustno-licevymi deformacijami v do- i posleoperacionom periodah [Psychological evaluation of patients with congenital and acquired maxillofacial deformities in the pre- and postoperative periods]. Stomatologija.76 (5): 35-39.

32. Nazarjan D.N., Harazjan A.Je., Jarancev S.V. 2016. Nemedlennaja nagruzka na kranial'nyh implantatah dlja ustranenija defektov lica [Immediate loading on cranial implants to repair facial defects. Annals of plastic, reconstructive and aesthetic surgery]. Annaly plasticheskoj, rekonstruktivnoj i jesteticheskoj hirurgii. 1: 90-91.

33. Nazarjan D.N., Jarancev S.V., Harazjan A.Je., Chernen'kij M.M. 2017. Implantacija s nemedlennoj nagruzkoj v anaplastologii [Implantation with immediate loading in anaplastology. Digital Dentistry]. Cifrovaja stomatologija. 6 (1): 80-85.

34. Nikolaeva E.N., Chuvilkin V.I., Carev V.N., Panin A.M., Hitarishvili M.V., Careva T.V. 2011. Jekspressija parodontopatogennyh bakterij I i II porjadka u pacientov s periimplantitami [Detection of parodontopathoges (I and II order) inpatients with periimplantitis]. Dental Forum. 4: 10-12.

35. Nurieva N.S., Filimonova O.I. 2008. Stomatologicheskaja pomoshh' pacientam so zlokachestvennymi obrazovanijami polosti rta pri specializirovannom lechenii [Dental care for patients with malignant tumors of the oral cavity with specialized treatment]. Ural'skij medicinskij zhurnal. 10 (50): $123-125$.

36. Paraskevich V.L., Artjushkevich A.S, Jackevich O.S. 2005. Metodika total'noj rekonstrukcii al'veoljarnogo otrostka verhnej cheljusti [The technique of total reconstruction of the alveolar process of the upper jaw]. Institut stomatologii. 2 (27): 18-23.

37. Pivovarov A.A., Arutjunov S.D., Muslov S.A., Raimova D.B., Kozlov S.S. 2014. Prochnostnye svojstva frezerovannyh zubocheljustnyh protezov iz konstrukcionnogo stomatologicheskogo materiala [Strength properties of milled dentures from constructional dental material]. Sovremennye problemy nauki i obrazovanija. 4: 326. URL: http://www.science-education.ru/118-14324 (data obrashhenija: 15.08.2014).

38. Reshetov I.V. 2016. Opuholi organov golovy i shei. Tehnologii lechenija, rekonstrukcii, reabilitacii pacientov: rekonstrukcija tkanej [The technique of total reconstruction of the alveolar process of the upper jaw]. Izd-vo OAO «Tverskoj poligraficheskij kombinat», $520 \mathrm{~s}$.

39. Solov'eva A.M. 2011. Periimplantit: jetapy dostizhenija konsensusa v diagnostike i lechenii [Periimplantitis: stages of consensus in diagnosis and treatment]. Klinicheskaja stomatologija. 1 (57): 50-52.

40. Harazjan A.Je., Arutjunov A.S., Lebedenko I.Ju., Arutjunov S.D. 2008. Jesteticheskoe formirovanie licevogo proteza pri defektah srednej zony lica [Aesthetic formation of the facial prosthesis with defects in the middle zone of the face]. Institut stomatologii. SPb. 3 (40): 42-45. 
41. Harazjan A.Je., Nazarjan D.N., Jarancev S.V., Chernen'kij M.M. 2019. Novyj sposob ustranenija defektov nizhnej zony lica u somaticheski otjagoshhennyh pacientov [A new method to correct lower face defects in somatically burdened patients]. Annaly hirurgii, 24 (2): 94-99.

42. Shanidze Z.L. 2019. Sovershenstvovanie stomatologicheskogo ortopedicheskogo lechenija pacientov s polnym otsutstviem zubov i posleoperacionnymi defektami verhnej cheljusti [Improving dental orthopedic treatment of patients with complete absence of teeth and postoperative defects of the upper jaw]. Avtoref. diss. ... kand. med. nauk: (14.01.14 - stomatologija). M.: CNIIS. 24 s.

43. Buzayan M.M. 2013. Prosthetic management of mid-facial defects with magnet-retained silicone prosthesis. Journal of Prosthetics and Orthotics International.

44. Forbes K. 1997. Palliative care in patients with cancer of the head and neck. Clin. Otolaryngol. 22: 117 . Oxford.

45. Kerawala C., Newlands C. 2010. Oral and Maxillofacial Surgery, Oxford University Press,

46. Palousek D., Rosicky J., Koutny D. 2014. Use of digital technologies in nasal prosthesis manufacturing. Prosthetics and Orthotics International, 38 (2): 171-175.

47. Tariq Aziz, Mark Waters, Robert Jagger, 2003. Analysis of the properties of silicone rubber maxillofacial prosthetic materials. Journal of Dentistry, 31 (1): 67-74.

48. Watkinson J.C., Gaze M.N., Wilson J.A. 2000. Reconstraction. In Stell P.M. and Maran A.G.D., Head and neck surgery, 4th edn, pp. 101-57. Battwerworth - Heinmann, Oxford University Press, Oxford.

\section{Ссылка для цитирования статьи Link for article citation}

Арутюнов С.Д., Леонтьев В.К., Цимбалистов А.В., Дробышев А.Ю., Барденштейн Л.М., Харазян А.Э., Рапута А.С., Царев В.Н. 2020. Профессиональные риски хирургического и ортопедического лечения пациентов с приобретенными дефектами лица и челюстей (обзор литературы). Актуальные проблемы медицины, 43 (2): 285-303. DOI 10.18413/2687-0940-2020-43-2-285-303.

Arutyunov S.D., Leontiev V.K., Tsimbalistov A.V., Drobyshev A.Yu., Bardenshtein L.M., Kharazyan A.E., Raputa A.C., Tsarev V.N. 2020. Occupational risks in the rehabilitation of patients with acquired defects of the face and jaw (review of literature). Challenges in Modern Medicine, 43 (2): 285-303 (in Russian). DOI 10.18413/2687-0940-2020-43-2-285-303. 